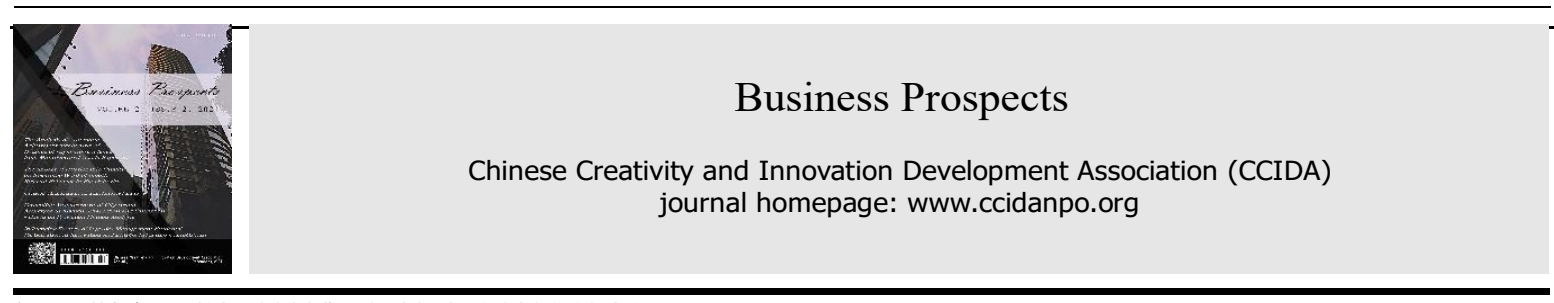

https://doi.org/10.52288/bp.27089851.2021.12.05

\title{
The Status Quo, Problems and Countermeasures of the B\&B Industry in China
}

\author{
Wei-Jing Zhao ${ }^{1, *}$ \\ ${ }^{1}$ Associate Professor of School of International Business, Xiamen University Tan Kah Kee College \\ * Correspondence: nancy@xujc.com
}

Received: 2021.11.06; Accepted: 2021.11.17; Published: 2021.12.01

\begin{abstract}
With the rapid development of the domestic economy and the continuous improvement of the people's living standards, China's all-in tour continued to warming. As the segment of tourism accommodation products, the $\mathrm{B} \& \mathrm{~B}$ is in the guidance of rural revitalization policies to show vigorous vitality. This paper discusses the development status and existing problems of China's B\&B Industry in recent years, and put forward countermeasures.
\end{abstract}

Keywords: B\&B Industry; Development; Status Quo; Problem; Countermeasures

\section{Introduction}

There are three views concerning the origins of the B\&B: one believes that the homestay is from British B\&B (Bed and Breakfast) and is a family-style hotel for breakfast and accommodation; another believes that it is from America, such as Family Hotel, Family Inn House, Hotel House, Stay Guest house etc. (Wu and Yu, 2018). There is also a kind of condensation from Japan, which is derived and developed by some tourist enthusiasts in order to meet the needs of the spa and tourism area. It is known as "Minshuku". The B\&B industry in Taiwan has been greatly affected by Japan. It is constantly innovating in the development process and now has developed relatively mature. The starting of B\&B in China is getting late and the meaning is also mainly introduced from Taiwan. Later, with the improvement of living standard and quality, consumers are no longer satisfied with the services provided by the traditional farmhouse, farm and tourist attractions, but turn to the exquisite and high-grade B\&B leisure tourism. Therefore, B\&B has mushroomed all over the country. In China, B\&B is named "Farmhouse", "Residential Inn" and other terms rather than "Family Hotel". They have the following four common points: 1.Family operation, usually the manager is the owner; 2.Guests can communicate with the host to a certain extent; 3.Small operation scale; 4.Provide a variety of special services.

\section{The Important Significance of Developing B\&B Industry}

\subsection{Influence Accommodation Pattern, Promote Market Competition}

With the rapid economic development of China, the quality of living standard is continuously improved. The acceleration of urbanization process that makes people who daily faces heavy life stress and fast-paced lifestyle moves towards comfort, quiet and quiet rural life. As a result, short-distance travel has emerged in recent years, which makes China gradually span from country with a shortage of tourism to a reach in tourism. With the rapid increases in domestic tourism by $10 \%$ and as one of the types of new era, the total amount is huge although the amount of the monomer investment in B\&B is not large. It not only provides effective supply for China's accommodation market but also impacts on China's accommodation pattern. It has played role on further refinement and competition for the supply and demand in the accommodation market in China. 


\subsection{Promote Region-Wide Tourism, Help Rural Revitalization}

With the arrival of the new era of mass tourism as well as an important part and new focus of tourism development, $\mathrm{B} \& \mathrm{~B}$ is becoming an important starting point to promote the development of region-wide tourism, an important channel to help implement the rural revitalization strategy, and an important way to promote culture and tourism consumption. The development of B\&B industry can not only improve the quality of rural tourism but also promote the transformation of rural economic structures. It plays great promotion on the increases in farmers' income, the overall industrial chain, the development of rural tourism industry, and the development of rural economy. As a shining name card of Hunan B\&B, Zhangjiajie "No.5 Valley" has received tourists from 57 countries and regions in the past 8 years that greatly promoted the development of local economy. Yangshuo of Guilin, as one of the earliest international tourist destinations in China, had its first village homestay in the mid-1990s. After years of development, Yangshuo by 2020 has registered more than 1,500 accommodation units including approximately $1,000 \mathrm{~B} \& \mathrm{Bs}$. With the growth of the B\&B industry, the local villagers and poor households in Yangshuo have received the dividends brought by the development, and the rural economic structure has also changed. The most immediate impact of the $\mathrm{B} \& \mathrm{~B}$ development has been the creation of 10,000 local jobs.

\subsection{Inherit Local Folk Culture, Reshaping Country Charm}

The development of traditional folk culture is based on profound historical accumulation. Regional characteristics often represent a region's cultural style and character, and is the concentrated embodiment of the cultural spirit of this region. B\&B reflects the uniqueness of local culture to a certain extent. It concentrates local traditional culture, historical culture, geographical culture, and national culture to bring excellent impression of the experience Therefore, B\&B with more culturally characterized will be favored by more tourists. In turn, it promotes the specialization process of China's accommodation.

According to the "Basic Requests and Evaluation of Tourism B\&B" released by the National Tourism Administration, B\&B should be required in basic health, safety, and quality of service. Therefore, from a social perspective, the $B \& B$ is a bridge that extends to rural areas. To develop country tourism, villagers must abandon their bad habits for many years and penetrate modern civilization in production and life thus can comprehensively enhance the level of rural social management.

\section{The Development Status of B\&B Industry}

Domestic B\&B is mainly started from early 2010. The distribution of B\&B in China is consistent with the overall development of China's tourism industry. It mainly focused on the regional area of tourism: east region such as Beijing and Zhejiang, southeast region such as Fujian and Guangdong, southwestern region such as Yunnan and Sichuan, and some cities in northwestern and northeast regions. In recent years, with the upgrading of China's tourism consumption and the transformation of tourists' consumption levels, domestic B\&B industry continues to boost. According to the survey data, the total number of $B \& B$ in the mainland is 42,734 with 11 provinces and cities more than 1,000 (Liu, 2018). The top ten in number of B\&B in China is Yunnan, Zhejiang, Beijing, Sichuan, Shandong, Fujian, Hebei, Guangdong, Guangxi, and Hunan. Among them, Yunnan ranks first with 6,466 in guests. Zhejiang and Beijing rank second and third with in 5,669 and 3,587 in guests, respectively. According to different division criteria, there are different types of $B \& B$ in China. There are scenic $B \& B$ and suburbs if it is divided by geographical location; home type, investment and cluster if it is grouped by business category; ordinary B\&B, boutique B\&B and Destination if it is classified by level; human resources, natural resources, agricultural picking sights and new rural construction types if it is distinguished by characteristics.

\section{The problems of China's B\&B Industry Development}

\subsection{Lack of Effective Supervision of B\&B Industry, Some Quality Is Low}

$\mathrm{B} \& \mathrm{~B}$ has the dual functions of tourism and hotel accommodation. However, unified practice for positioning, approval and management of homestay industry standards, and clear regulatory provisions are strongly required. At present, only a few provinces and cities have clear management methods and most of the township governments are short of regulatory policy and legal basis. Most of the homestay are reconstructed by the civilian house and there is no two-way escape channel and simple fire sprinkler device, which might bring hidden trouble of fire. What's more, there is imperfect infrastructure existing in some of the facilities, 
such as bathroom leaks, poor soundproofing, and out of date of internal planning. Sanitary conditions, in particular, have become the focus of complaints on China's B-B platform.

\subsection{The Quality of the Operator is Uneven, the Professional Talent is Lacking}

Since most of the B\&B operators are engaged in the benefit of the sensibility, they are lack of professional background knowledge and have no in-depth study on the B\&B industry (Huang, 2020). The lack of professional talents has caused various problems in the business operations. Employee management and training, for example, are not professional causing a weak service awareness. As extension of the B\&B product, service quality is an important medium that customers visually feel the quality of it, which is the vivid presentation of the soul of the B\&B. Therefore, employee's words and deeds that should be in line with the style of B\&B, the implementation that should satisfy the work requirements of the $B \& B$, and the service that should meet the customer needs. These provide good experiences for the benefit of consumers and the long-term stability operation. However, based on the quality and professionalism of the B\&B operators, the limitations of their staff training and management greatly hinder the further development of China’s B\&B industry.

\subsection{The Lack of Features, Single Homogenization}

With the upgrade of consumption, people have changed from tourism to leisure vacation. They pay more attention to travel quality and experience. In order to meet the needs of visitors micro-holiday under new trend of tourism quality requires, operators should provide a personalized experience with temperature-friendly care in the design. However, B\&Bs in China are much similar. They usually have single accommodation function, no in-depth in resource mining, blindly following behavior, and similar service content. As B\&B owners lack interaction with tourists. It is difficult for visitors to produce different unique experience, and B\&B also loses cultural charm originally carried.

\subsection{Brand Awareness is Weak, Lack of Popularity}

Most B\&B brands in China are not well known, and the means of promotion and marketing of B\&B operators are relatively simple and mainly rely on repeat customers, issuing business cards and word-of-mouth publicity. The essence of the B\&B is the service industry. After the explosive growth of the industry, it will transform from extensive, homogenized, and individual operations to boutique, chain, and standardized. China's B\&B will also face the industry's large shuffle. If it wants to stand out in the fierce market competition, branding will be the key element. If B\&B wants to have a healthy development, it must have brand awareness, develop in the direction of branding, and promote the development of the property industry by enhancing brand value.

\section{The Development Suggestions of China's B\&B Industry}

\subsection{Adhere to A Problem-Oriented Approach and Implement Oversight Measures}

In view of the weak policy and regulations in China's B\&B as well as the lack of corresponding constraints, as an important part of tourist accommodation, the $B \& B$ needs to rely on the government to escort the corresponding policy mechanisms to uniform the order of development. Therefore, relevant government departments should introduce laws and regulations in the industry, formulate service standards, and provide regulations for the business qualifications, operational quality, service supervision of the B\&B to improve the government's supervision system for the B\&B industry ( $\mathrm{Wu}, 2018)$.

\subsection{Pay Attention to Non-Government Agencies, Organize and Guide B\&B Such as the B\&B Association}

The industrial organization has played an important organizational and guiding role in the development of B\&B in Japan, Europe and the United States. Therefore, China can also protect the benefits of the B\&B operators through the establishment of a non-governmental organization such as B\&B association. The association can develop a huge role in cultivating the elite talents in the budget and promote the development of the huge industry. In addition, it can also be combined with all kinds of academic research institutions, actively promote communication collaboration with the academic circles, and encourage the benefits of the $\mathrm{B} \& \mathrm{~B}$ operators to participate actively in order to improve their professional quality and to deepen the consciousness. 


\subsection{Industry Construction Combined with Brand Marketing}

For B\&B industry construction and development, it is a comprehensive and livable system based on local territory and consumer demand rather than a simple superposition. Therefore, in the development of the B\&B industry, there must be B\&B and socially established support industry as well as synchronous planning, synchronous construction to promote the sustainable development of the B\&B industry. In addition, while building a brand marketing awareness in the B\&B industry, it is necessary to understand that brands are not only intangible assets but also the core competitiveness of the company. The industry must start its own brand as well as improve its market value and industry influence through brand marketing.

\subsection{Realize Differentiated Operations and Integrate Local Ethnic Characteristics into the Brand Construction of $B \& B$}

The most important factor of homestay tourism is to develop the characteristics of local villages with unique style and tourism experience so as to improve the competitiveness of homestay in the tourism market for considerable development. Therefore, to explore the characteristic culture in depth and to realize differentiated operations can avoid homogenization competition as well as meet the personalized consumer demand. This requires the $\mathrm{B} \& \mathrm{~B}$ operators to highlight distinctive, unique local culture and heavy history during the design and development of the $\mathrm{B} \& \mathrm{~B}$ to become the highlight of the guests to attract tourists.

\section{Conclusions}

$\mathrm{B} \& \mathrm{~B}$ is based on the knowledge economy and natural ecological environment of the creative life category. The development of B\&B not only cater to the needs of tourists experience freedom but also to meet the demand of consumer upgrades, personalized consumption demand, and the people's demand for a better life. The value of a $\mathrm{B} \& \mathrm{~B}$ at present in our country is more and more. However, due to the lack of reasonable planning and standardization, China's B\&B industry lacks characteristics and highlights, affecting brand competitiveness and consumer experience. Only by reflecting on the deficiency of B\&B development and actively developing B\&B with folk characteristics can we promote our country's rural tourism industry and revitalize the rural economy.

\section{References}

1. Huang, Q. Y. (2020). Research on the Status Quo and Countermeasures of China's B\&B Development. Industry and Technology Forum, 22: 12-13.

2. Liu, W. X. (2018). Analysis of the Development Status and Strategy of B\&B in China. Modern Market, 5: 41-42.

3. Wu, Q. J. (2018). Research on Tourism Development Based on Folk Culture (Unpublished Master Thesis). Hubei Province: Huazhong Normal University.

4. Wu, X. Y., \& Yu, L. L. (2018). The Concept of the Home, the Evolution and the Development of Connotation. Tourism Research, 2: 84-94.

(Editor: Jiahua Yang) 